\title{
Chemical and transient spectroscopic evidence for radical and ionic pathways in the photolysis of 3-halo-2,3-dihydrobenzopyran-4-ones
}

\author{
Julio Delgado, Amparo Espinós, M. Consuelo Jiménez, and Miguel A. Miranda* \\ Departamento de Química/Instituto de Tecnología Química UPV-CSIC, Universidad Politécnica \\ de Valencia, Apartado 22012, E-46071-Valencia, Spain \\ E-mail: mmiranda@gim.upv.es
}

Deducated to Waldemar Adam's 70th birthday

\begin{abstract}
Photolysis of 3-halo-2,3-dihydrobenzopyran-4-ones 1a,b and 2a,b in acetonitrile and hexane led to dehalogenated dihydrobenzopyran-4-ones $\mathbf{3 a , b}$ and benzopyran-4-ones $\mathbf{4 a}, \mathbf{b}$. Their formation is accounted for in terms of primary cleavage of the carbon halogen bond to give $\alpha$-carbonyl radicals (I) and/or cations (II). Intermediates II, precursors of $\mathbf{4}$, can be generated either directly by heterolysis or by initial homolysis followed by electron transfer. The ionic routes are more favored in acetonitrile than in hexane. The involvement of radical and ionic pathways in the photochemistry of 3-halo-2,3-dihydrobenzopyran-4-ones is supported by detection of $\mathrm{Br}_{2}^{-}$in the laser flash photolysis experiments performed on $\mathbf{2 a}$.
\end{abstract}

Keywords: $\alpha$-Haloketones, laser flash photolysis, photocleavage, photoelimination photoreduction

\section{Introduction}

As an extension of our previous studies on the photochemistry of benzopyran-derived compounds, ${ }^{1-4}$ we have been interested in the light induced fragmentation of 3-halo-2,3dihydrobenzopyran-4-ones (3-halochromanones), which leads to the corresponding $\alpha$-keto radicals and/or cations; these species are key intermediates in the electron transfer processes followed by 4 -acetoxychromenes. ${ }^{4}$ Short lived intermediates of this type are also relevant because they are thought to play an important role in some processes of biosynthetic interest in the field of flavonoids, such as flavone-isoflavone isomerization or oxidation of the $\mathrm{C} 3$ bridge of flavanones affording flavones or flavonols. ${ }^{5,6}$ The photochemistry of some 3-bromochromanones has been described by us in the past. ${ }^{7,8}$ Here, we wish to report on the photochemical behavior of four 3-bromo- and 3-chloro-2,3-dihydrobenzopyran-4-ones under different conditions. Thus, in 
1a and 2a the only substituent of the dihydrobenzopyran ring is chlorine or bromine respectively, while compounds $\mathbf{1 b}$ and $\mathbf{2 b}$ also possess a trans- phenyl group attached to the 2-position (Chart $1)$.

$\begin{array}{lll}\text { 1a: } R=H, X=C l & \mathbf{1 b}: R=P h, X=C l \\ \text { 2a: } R=H, X=B r & \text { 2b: } R=P h, X=B r\end{array}$

\section{Chart 1}

\section{Results and Discussion}

Compounds 1a,b and 2a,b were obtained following known procedures, ${ }^{9,10}$ as detailed in the experimental section. Photolysis of these substrates was carried out for $1 \mathrm{~h}$ in acetonitrile or hexane at 254 or $350 \mathrm{~nm}$. The results are summarized in Table 1 and Figure 1.

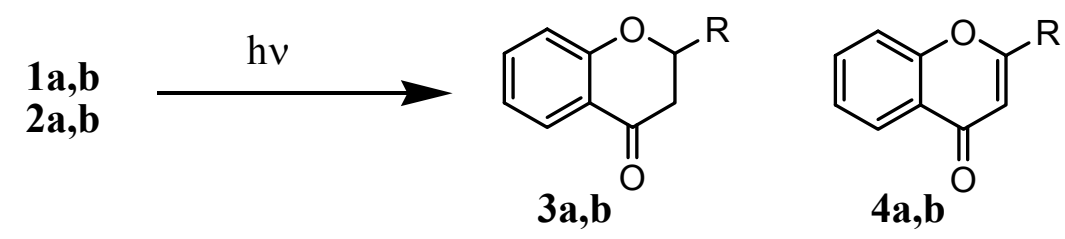

3a, 4a: $\mathrm{R}=\mathrm{H}$

3b, $4 \mathbf{b}: \mathrm{R}=\mathrm{Ph}$

Figure 1. Photolysis of 3-halochromanones $\mathbf{1 a , b}$ and/or $\mathbf{2 a , b .}$

Irradiation of $\mathbf{1 a}$ in acetonitrile led exclusively to chromone $\mathbf{4 a}$ (Table 1, entries 1 and 2). However, when hexane was used as solvent (Table 1, entries 3 and 4), appreciable amounts of the corresponding dihydro derivative (4-chromanone, 3a) were also found in the photolysate. In the case of the bromo derivative $\mathbf{2 a}$, photolysis led to mixtures of $\mathbf{3 a}$ and $\mathbf{4 a}$ under the different conditions employed (Table 1, entries 5-8), but the ratios 4a/3a were considerably higher in acetonitrile than in hexane ( $c a$. 25:1 in acetonitrile to 6:1 in hexane). The presence of a phenyl substituent at the 2-position of the dihydrobenzopyran ring of $\mathbf{1 a}$ or $\mathbf{2 a}$ (as in compounds $\mathbf{1 b}$ or $\mathbf{2 b}$ respectively) did not change the trend; again the benzopyran derivative (flavone, $\mathbf{4 b}$ ) was the major photoproduct although flavanone $\mathbf{3 b}$ (resulting from reductive dehalogenation) was also formed; the latter was found in higher amounts when hexane was used as solvent (Table 1, entries 9-16). Conversion was always higher for the bromochromanones than for their chloro analogues. This is in good agreement with the lower energy of the $\mathrm{C}-\mathrm{Br}$ bond $v s$. the of $\mathrm{C}-\mathrm{Cl}$ bond. ${ }^{11}$ On the other hand, the presence of the phenyl group at the 2-position resulted in higher 
conversions; this can be attributed in part to the additional light absorption by the aromatic substituent.

Table 1. Photolysis of 3-halochromanones 1a,b and 2a,b under different conditions

\begin{tabular}{cccccc}
\hline Entry & Compound & Conditions $^{*}$ & Conversion & $\mathbf{3}$ & $\mathbf{4}$ \\
\hline 1 & $\mathbf{1 a}$ & $\mathrm{A}$ & 37 & - & 100 \\
2 & $\mathbf{1 a}$ & $\mathrm{B}$ & 16 & - & 100 \\
3 & $\mathbf{1 a}$ & $\mathrm{C}$ & 55 & 13 & 87 \\
4 & $\mathbf{1 a}$ & $\mathrm{D}$ & 47 & 15 & 85 \\
5 & $\mathbf{2 a}$ & $\mathrm{A}$ & 63 & 4 & 92 \\
6 & $\mathbf{2 a}$ & $\mathrm{B}$ & 54 & 4 & 95 \\
7 & $\mathbf{2 a}$ & $\mathrm{C}$ & 90 & 15 & 85 \\
8 & $\mathbf{2 a}$ & $\mathrm{D}$ & 81 & 29 & 71 \\
9 & $\mathbf{1 b}$ & $\mathrm{A}$ & 64 & - & 100 \\
10 & $\mathbf{1 b}$ & $\mathrm{B}$ & 46 & - & 100 \\
11 & $\mathbf{1 b}$ & $\mathrm{C}$ & 70 & 36 & 64 \\
12 & $\mathbf{1 b}$ & $\mathrm{D}$ & 56 & 22 & 78 \\
13 & $\mathbf{2 b}$ & $\mathrm{A}$ & 95 & 2 & 98 \\
14 & $\mathbf{2 b}$ & $\mathrm{B}$ & 90 & 3 & 97 \\
15 & $\mathbf{2 b}$ & $\mathrm{C}$ & 100 & 13 & 87 \\
16 & $\mathbf{2 b}$ & $\mathrm{D}$ & 93 & 20 & 80 \\
\hline
\end{tabular}

*A: acetonitrile, $\lambda=254 \mathrm{~nm}$; B: acetonitrile, $\lambda=350 \mathrm{~nm}$; C: hexane, $\lambda=254 \mathrm{~nm}$ : D: hexane, $\lambda=350 \mathrm{~nm}$.

In general, formation of $\mathbf{3 a , b}$ and $\mathbf{4 a , b}$ can be rationalized as follows: primary photochemical cleavage of the carbon-halogen bond affords radicals (I) and/or ions (II). ${ }^{12-18}$ The latter intermediates can be generated either directly by heterolysis (route ii) or by initial homolysis (i) followed by electron transfer (iii), as shown in Figure 2. Clearly, routes (ii) and (iii) should be favored in more polar solvents. Therefore, $\mathbf{4 a , b}$ are obtained in higher yields in acetonitrile than in hexane.

The involvement of both radical and ionic pathways in the photochemistry of $\alpha$-haloketones has been previously suggested in the literature. ${ }^{12-18}$ Looking for a clear evidence supporting the involvement of these routes in the photolysis of 4-halochromanones $\mathbf{1} \mathbf{a}, \mathbf{b}$ and $\mathbf{2 a , b}$, laser flash photolysis (LFP) experiments were performed in acetonitrile and hexane at $266 \mathrm{~nm}$. Detection of $\mathrm{X}_{2}{ }^{--}$species (resulting from combination of $\mathrm{X}^{\cdot}$ and $\mathrm{X}^{-}$) would provide a proof for the mixed radical/ionic mechanism. This was actually found to be the case. For instance, starting from $2 \mathbf{a}$, a transient with maximum at $360 \mathrm{~nm}$ in acetonitrile (350 $\mathrm{nm}$ in hexane) was observed (Figure 3) after 266 LFP under $\mathrm{N}_{2}$. It was attributed to $\mathrm{Br}_{2}{ }^{-}$, by comparison with the spectrum reported in the literature for this species, generated from 1,2-dibromoethane. ${ }^{19,20}$ Obviously, the observed 
$\mathrm{Br}_{2}{ }^{-\cdot}$ is formed by recombination of the bromine atom generated after homolytic cleavage (route i) with bromide ion produced in the heterolytic pathway (ii) or after electron transfer (route iii). The lifetime of this species ranged in the microsecond scale.

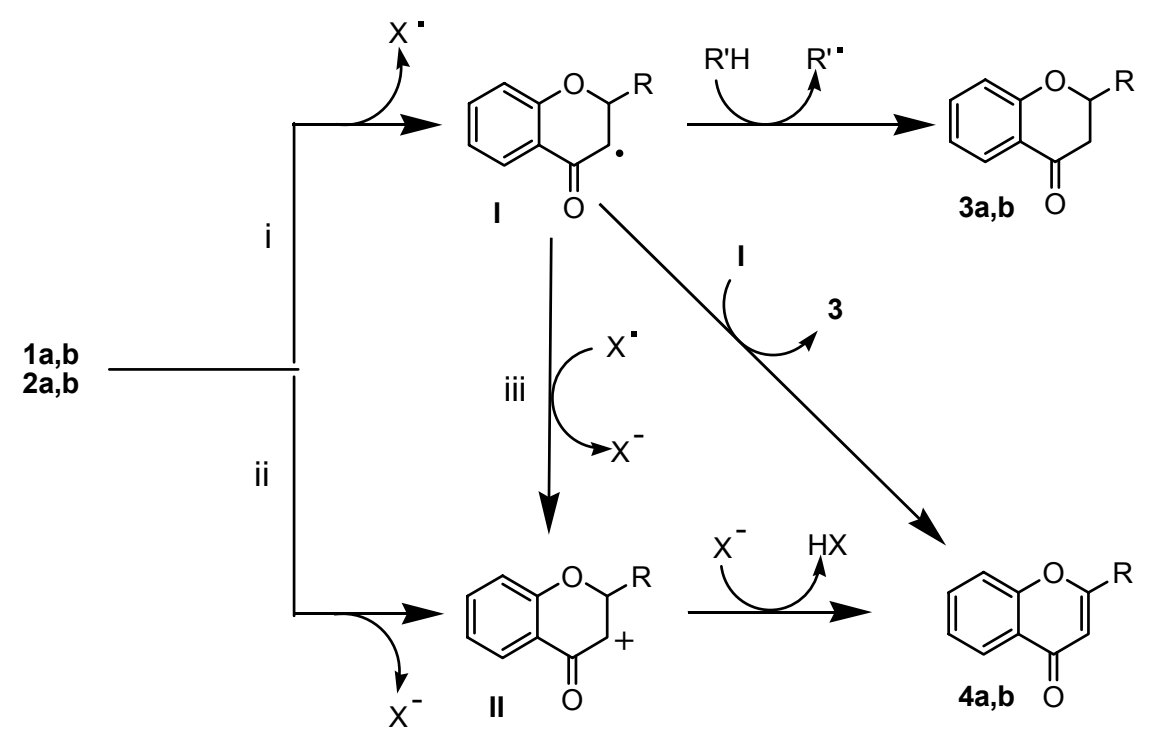

Figure 2. Main routes leading to $\mathbf{3 a}, \mathbf{b}$ and $\mathbf{4 a}, \mathbf{b}$.

In order to generate $\mathrm{Br}_{2}{ }^{--}$in higher yield, a solution of $\mathbf{2 a}$ in acetonitrile in the presence of a bromide salt $\left(\mathrm{Et}_{4} \mathrm{NBr}\right)$ was submitted to LFP. As expected, the shape and position of the band was the same as that recorded in the absence of bromide, but much more intense. On the other hand, when hexane was used as solvent, the optical density (OD) at 360 was higher than in acetonitrile; this points to an enhancement of the radical pathway, which leads to higher amounts of 3a (Table 1, entries 7,8). In Figure 4, a comparison between the top $\triangle \mathrm{OD}$ values (LFP, signal monitored at $360 \mathrm{~nm}$ ) for $\mathbf{2 a}$ in acetonitrile (A), hexane (B) and acetonitrile in the presence of $\mathrm{Et}_{4} \mathrm{NBr}(\mathrm{C})$ is shown.

In summary, both radical and ionic pathways are involved in the photolysis of 3halochromanones. This is supported by chemical evidence (formation of chromanones and chromones), as well as by detection of $\mathrm{Br}_{2}^{-}\left(\lambda_{\max }=360 \mathrm{~nm}\right)$ in the laser flash photolysis experiments. 


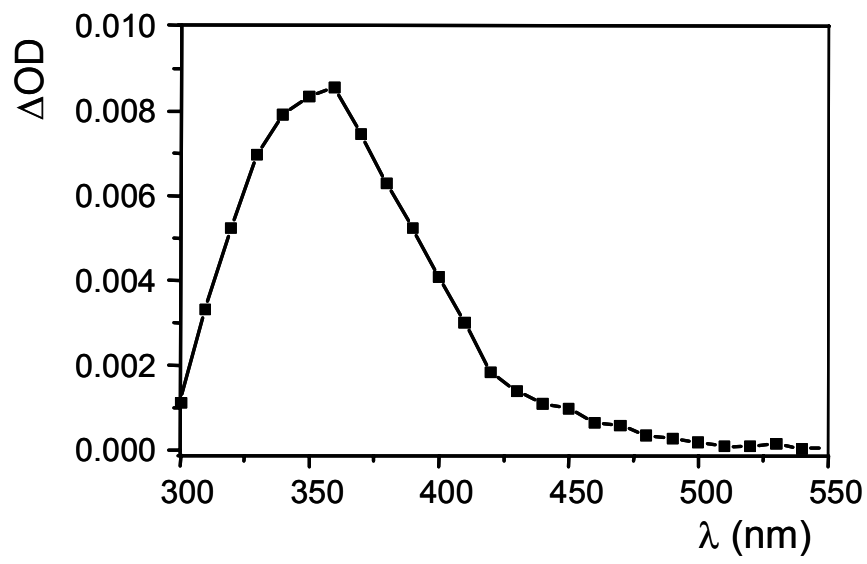

Figure 3. Laser flash photolysis of $\mathbf{2 a}$ in $\mathrm{MeCN} / \mathrm{N}_{2}$. Transient spectra obtained $1.3 \mu \mathrm{s}$ after the laser pulse.

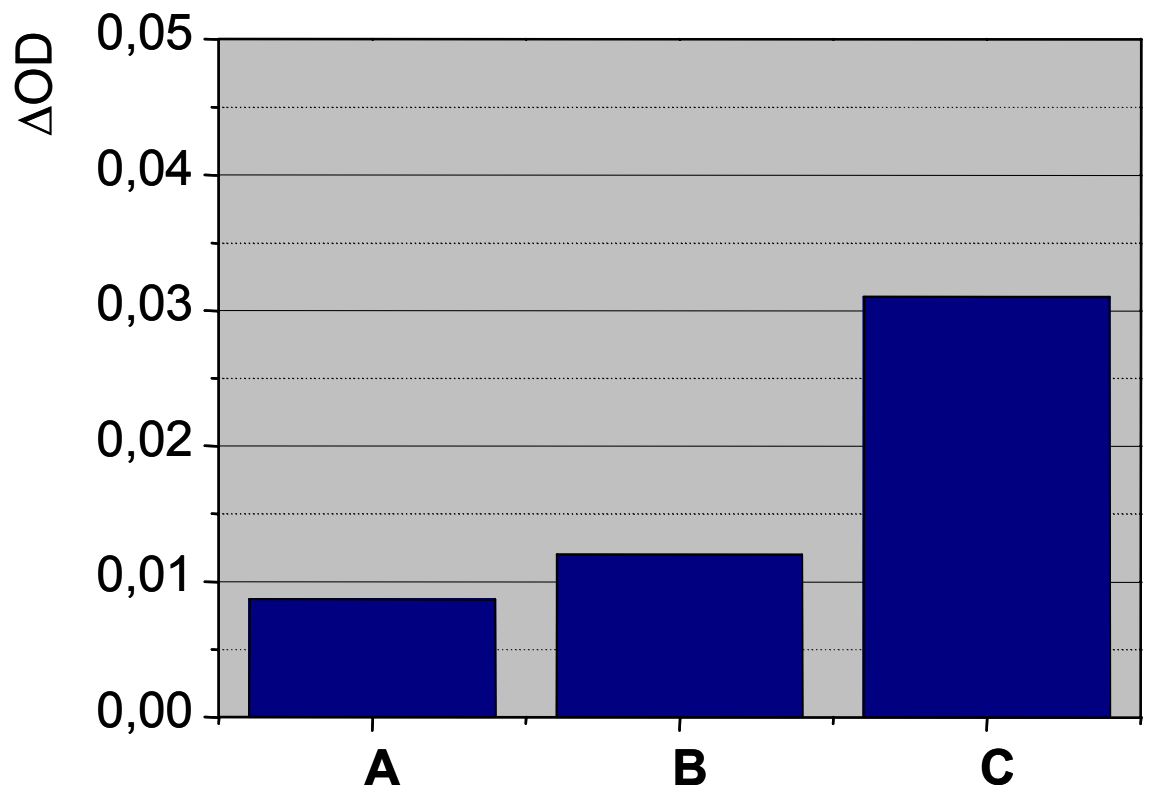

Figure 4. Top $\triangle \mathrm{OD}$ values (signal at $360 \mathrm{~nm}$ ) of the transient species formed after $266 \mathrm{LFP}$ of $\mathbf{2 a}$ in acetonitrile (A), hexane (B) and acetonitrile/ $\mathrm{Et}_{4} \mathrm{NBr}(\mathrm{C})$.

\section{Experimental Section}

General Procedures. Solutions of $\mathbf{1} \mathbf{a}, \mathbf{b}$ and $\mathbf{2 a , b}(5 \mathrm{mM})$ in hexane or acetonitrile were irradiated for $1 \mathrm{~h}$ through quartz, inside a Luzchem multilamp photoreactor, with the light from 4 $8 \mathrm{~W}$-lamps emitting mainly at $254 \mathrm{~nm}$ (monochromatic) or $350 \mathrm{~nm}$ (Gaussian distribution). The course of the reaction was followed by GC, GC-MS and ${ }^{1} \mathrm{H}-\mathrm{NMR}$; the conversion, product 
distribution and mass balance were determined using adequate standards. The structures of the photoproducts were confirmed by comparison with retention times and fragmentation patterns of authentic samples.

Laser flash photolysis experiments were performed by using a Q-switched Nd:YAG laser (Quantel Brilliant, $266 \mathrm{~nm}, 14 \mathrm{~mJ}$ per pulse, $5 \mathrm{~ns}$ fwhm) coupled to a mLFP-111 Luzchem miniaturized equipment. All transient spectra were recorded employing $10 \times 10 \mathrm{~mm}^{2}$ quartz cells with $4 \mathrm{~mL}$ capacity. The absorbance of the halochromanones was found to be $c a .0 .2$ at the laser wavelength. The experiments were carried out in hexane or acetonitrile at room temperature (22 ${ }^{\circ} \mathrm{C}$ ) and under inert atmosphere.

3-Chloro-2,3-dihydrobenzopyran-4-one (1a). ${ }^{21}$ To $1.48 \mathrm{~g}(10 \mathrm{mmol})$ of 4-chromanone in 20 $\mathrm{mL}$ of acetic acid, maintained under stirring, $1.03 \mathrm{~g}$ of manganese dioxide and $3.3 \mathrm{~mL}$ (42 mmol) of acetyl chloride were added. The mixture was maintained for $12 \mathrm{~h}$ at $20^{\circ} \mathrm{C}$. Then, $50 \mathrm{~mL}$ of a $\mathrm{NaHCO}_{3}$ aqueous solution were added, and the resulting suspension was extracted three times with methylene chloride. The crude mixture was submitted to column chromatography to afford $0.73 \mathrm{~g}$ of $1 \mathrm{a}(40 \%)$.

3-Bromo-2,3-dihydrobenzopyran-4-one (2a). ${ }^{22}$ A solution of $\mathrm{Br}_{2} \quad(1.0 \mathrm{~g}, 6.25 \mathrm{mmol})$ in 30 $\mathrm{mL}$ of $\mathrm{CCl}_{4}$ was added to a well stirred solution of 4-chromanone $(6.25 \mathrm{mmol})$ in $\mathrm{CCl}_{4}(30 \mathrm{~mL})$. After $2 \mathrm{~h}$, the reaction mixture was evaporated in vacuo, and $2 \mathrm{a}(1.37 \mathrm{~g}$. 60\%) was isolated by column chromathography using methylene chloride as eluent.

3-Chloro-2-phenyl-2,3-dihydrobenzopyran-4-one (1b). ${ }^{23}$ To $2.24 \mathrm{~g}$ (10 mmol) of 4-flavanone in $20 \mathrm{~mL}$ of acetic acid, maintained under stirring, $1.03 \mathrm{~g}$ of manganese dioxide and $3.3 \mathrm{~mL}$ (42 $\mathrm{mmol}$ ) of acetyl chloride were added. The mixture was maintained for $12 \mathrm{~h}$ at $20^{\circ} \mathrm{C}$. Then, $50 \mathrm{~mL}$ of a $\mathrm{NaHCO}_{3}$ aqueous solution were added, and the resulting suspension was extracted three times with methylene chloride. The crude mixture was submitted to column chromatography to give $0.91 \mathrm{~g}$ of pure $\mathbf{1 b}(35 \%)$.

3-Bromo-2-phenyl-2,3-dihydrobenzopyran-4-one (2b). ${ }^{24} \mathrm{~A}$ solution of $\mathrm{Br}_{2} \quad(1.0 \mathrm{~g}, \quad 6.25$ $\mathrm{mmol})$ in $30 \mathrm{~mL}$ of $\mathrm{CCl}_{4}$ was added to a well stirred solution of 4-flavanone $(6.25 \mathrm{mmol})$ in $\mathrm{CCl}_{4}$ $(30 \mathrm{~mL})$. After $2 \mathrm{~h}$, the reaction mixture was evaporated in vacuo, and $\mathbf{2 b}(1.61 \mathrm{~g}, 72 \%)$ was isolated by column chromathography using methylene chloride as eluent.

\section{Acknowledgements}

Financial support from the MEC (CTQ2004-03811) is gratefully acknowledged. 


\section{References}

1. 1. Climent, M. J.; García, H.; Iborra, S.; Miranda, M. A.; Primo, J. Heterocycles 1989, 29, 115 .

2. Miranda, M. A.; Primo, J.; Tormos, R. Tetrahedron 1989, 45, 7593.

3. Climent, M. J.; Garcia, H.; Iborra, S.; Miranda, M. A.; Primo, J. Tetrahedron 1991, 47, 9289.

4. Jiménez, M. C.; Miranda, M. A.; Soto, J.; Tormos, R. Tetrahedron 1994, 50, 7635.

5. Harborne, J. B; Mabry, T. J.; Mabry, H. The Flavonoids, Academic Press: New York, 1976.

6. Harborne J. B.; Mabry, T. J. The Flavonoids: Advances in Research, Chapman and Hall: New York, 1982.

7. Jiménez, M. C.; Miranda, M. A.; Tormos, R. J. Photochem. Photobiol. A: Chem 1995, 86, 225.

8. Jiménez, M. C.; Miranda, M. A.; Tormos, R. Heterocycles 1996, 43, 339.

9. Bellesia, F.; Ghelfi, F.; Pagnoni, U. M.; Pinetti, A. J. Chem. Res., Synopses 1990, 188.

10. García, H.; Martínez-Utrilla, R,: Miranda, M. A. Liebigs Ann. Chem. 1985, 589.

11. Murov, S. L.; Carmichel, I. Hugh, G. L. Handbook of Photochemistry, 2th Edition, Marcel Dekker, Inc.: New York, 1983.

12. Purohit P. C.; Sonawane, H. R. Tetrahedron 1981, 37, 873.

13. Izawa, Y.; Watoh, Y; Tomioka, H. Chem. Lett. 1984, 33.

14. García, H.; Martínez-Utrilla, R.; Miranda, M. A. Liebigs Ann. Chem. 1985, 589.

15. Morrison H.; de Cárdenas, L. J. Org. Chem. 1987, 52, 2590.

16. McGimpsey W. G.; Scaiano, J. C. Can. J. Chem. 1988, 66, 1474.

17. Zupan M.; Sket, B. Collect. Czech. Chem. Commun. 1988, 53, 1745.

18. Zupancic N.; Sket, B. J. Photochem. Photobiol. A: Chem. 1992, 63, 303.

19. Scaiano, J. C.; Barra, M.; Krywinski, M.; Sinta, R.; Calabrese G. J. Am. Chem. Soc. 1993, 115,8340 .

20. Scaiano, J. C.; Barra, M.; Calabrese; Sinta, R.G. J. Chem. Soc., Chem. Comun. 1992, 1418.

21. Cotterill, W. D.; Cottam, J.; Livingstone, R. J. Chem. Soc., Sect. C: Org. 1970, 1006 C.

22. Colonge, J.; Guyot, A. Bull. Soc. Chim. Fr. 1958, 329.

23. Tomlin, D. W.; Cantrell, J. S. Acta Crystal., Sect C 1990, C46, 519.

24. Reichel, L.; Weber, F. G. Zeitschr. Chem. 1966, 6, 223. 